EGU2020-21782

https://doi.org/10.5194/egusphere-egu2020-21782

EGU General Assembly 2020

(c) Author(s) 2020. This work is distributed under

the Creative Commons Attribution 4.0 License.

\title{
Investigate the influence of Polypropylene as fine Aggregate Replacement on the mechanical and thermal properties of the concrete mix
}

Reza Keihani and Ali Bahadori-Jahromi

University of West London, School of Computing and Engineering, United Kingdom of Great Britain and Northern Ireland (Reza.Keihani@uwl.ac.uk; Ali.Bahadori-Jahromi@uwl.ac.uk)

The consumption of natural resources in various industrial sectors has caused significant environmental issues to the atmosphere through emission and energy cost due to the extraction and transportation of the materials, along with the availability and long-term damage to the natural resources. In order to address this issue, various solutions have been provided to reduce the amount of consumed natural resources by replacing them with alternative materials such as plastic waste and plastic, as a burden to the environment, is one of those materials being well explored by other researchers due to its worldwide applications and destructive impacts on nature.

The industrial sectors, as massive consumers of natural resources and producers of plastic waste, have shown a continuous responsibility towards innovative alternatives for natural resources. In this regard, plastic materials such as Polyvinyl, Polystyrene, Polyethylene and Polypropylene have been investigated to replace coarse and fine aggregates in the construction without compromising the performance of the concrete mix.

This study aims to investigate the influence of Polypropylene as a fine aggregate replacement on the compressive and tensile strength of concrete cylinder samples after 28 days of curing and assess the impact of temperature on thermal properties of the 28 days cured samples. 